\title{
SANKSI ADMINISTRATIF TERHADAP TINDAKAN MALPRAKTIK DOKTER DAN RUMAH SAKIT DI INDONESIA
}

\author{
Marjan Miharja \\ Sekolah Tinggi Ilmu Hukum IBLAM \\ Jl. Kramat Raya No.25, RW.2, Kramat, Kec. Senen, \\ Kota Jakarta Pusat, Daerah Khusus Ibukota Jakarta 10450 \\ Email: marjan.miharja@yahoo.com
}

\begin{abstract}
Abstrak
Penelitian ini bertujuan untuk mengkaji bentuk-bentuk sanksi administratif terhadap tindakan malpraktik yang dilakukan oleh dokter dan rumah sakit dalam persepktif hukum positif Indonesia. Begitu pentingnya keberadaan dokter dalam kehidupan manusia, bukan berarti menjadikan dokter sebagai profesi yang tanpa imun. Artinya adalah dokter akan pasti mendapat sanksi apabila melakukan kesalahan walaupun pekerjaannya sangat dibuutuhkan oleh masyarakat. Etika, moralitas dan professional dalam profesi dokter harus tetap dijaga dalam segal keadaan. Metode yang digunakan adalah metode penelitian hukum normatif atau metode penelitian hukum kepustakaan adalah metode atau cara yang dipergunakan di dalam penelitian hukum yang dilakukan dengan cara meneliti bahan pustaka yang ada. Hasil penelitian menunjukkan tindakan malpraktik yang dilakukan oleh dokter dan rumah sakit telah memiliki mekanisme pertanggungjawaban hukum yang jelas sebagaimana diatur dalam Undang-undang Nomor 29 Tahun 2004 Tentang Praktek Kedokteran. Secara administratif, segala bentuk malpraktik yang dilakukan oleh dokter dan rumah sakit dapat diancam dengan sanksi hukuman pidana, perdata, sanksi administratif, dan denda. Adapun bagi rumah sakit, dapat dijatuhi sanksi secara langsung dan tidak langsung. Pada tingkatan yang lebih final, sanksi administratif dari tindakan malpraktik yang dilakukan oleh dokter dan rumah sakit dapat berujung pada pencabutan izin praktik.
\end{abstract}

\section{Kata kunci: Sanksi Administratif, Malpraktik, Dokter, Rumah Sakit.}

\section{Abstract}

This study aimed to examine the forms of sanctions for malpractice committed by doctors and hospitals in the perspective of positive Indonesian law. The method used is the normative legal research method or the library legal research method is the method or method used in legal research conducted by using existing library materials. The results showed malpractice actions carried out by doctors and hospitals have clear legal responsibilities stipulated in Act Number 29 of 2004 concerning Medical Practices. Administratively, all forms of malpractice carried out by doctors and hospitals can be threatened with imprisonment, civil, administrative sanctions, and fines. As for hospitals, they can be sentenced directly and indirectly. In the later, final stages, the final stages of court decisions made by doctors and hospitals can be carried out on license revocation.

Keywords: Malpractice, Administrative Sanctions, Doctors, Hospitals.

\section{PENDAHULUAN}

Dokter sebagai anggota profesi yang mengabdikan ilmunya untuk kepentingan umum, mempunyai kebebasan dan kemandirian yang berorientasi kepada nilai-nilai kemanusiaan sesuai dengan kode etik kedokteran. Kode etik kedokteran ini bertujuan untuk mengutamakan 
DEIEGA LATA

Jurnal Ilmu Hukum

FAKULTAS HUKUM UMSU
Sanksi Administratif Terhadap...(Marjan Miharja)

Volume 5 Nomor 1, Januari - Juni 2020, 51-56 DOI: https://doi.org/10.30596/dll.v5i1.344.5

kepentingan dan keselamatan pasien, menjamin bahwa profesi kedokteran harus senantiasa dilaksanakan dengan niat yang luhur dan dengan cara yang benar (Soetrisno, 2010, h. 5).

Seorang dokter sebelum melakukan praktek kedokterannya atau pelayanan medis telah melakukan pendidikan dan pelatihan yang panjang, sehingga masyarakat khususnya pasien banyak sekali menggantungkan harapan hidup dan/atau kesembuhan kepada dokter. Namun seperti diketahui, dokter tersebut sebagai manusia biasa yang dapat luput dalam melaksanakan tugas kedokterannya. Seperti pasien yang memiliki kemungkinan cacat atau meninggal dunia setelah ditangani dokter dapat saja terjadi, walaupun dokter telah melakukan tugasnya sesuai standar profesi atau standar pelayanan medik yang baik. Keadaan semacam ini biasa disebut sebagai resiko medik, namun terkadang dimaknai lain oleh pihak-pihak di luar profesi kedokteran sebagai medical malpractice (Machmud, 2008, h. 23-24).

Profesi dokter dan dokter gigi juga memiliki peraturan disiplin profesional yang diatur dalam Peraturan Konsil Kedokteran Indonesia No. 4 Tahun 2011 tentang Disiplin Profesional Dokter dan Dokter Gigi. Atas segala ketentuan terkait pedoman profesi-profesi di atas (baik yang ada dalam peraturan perundang-undangan maupun kode etik), terdapat pihak yang akan melakukan pengawasan dan menjatuhkan sanksi atas pelanggaran ketentuan profesi-profesi tersebut. Biasanya terdapat organisasi profesi atau badan khusus yang dibentuk untuk mengawasi profesi tersebut. untuk profesi dokter serta dokter gigi dilakukan oleh Majelis Kehormatan Disiplin Kedokteran Indonesia (Pasal 1 angka 3 Pedoman Organisasi dan Tatalaksana Kerja Majelis Kehormatan Etika Kedokteran Indonesia).

Organisasi profesi atau badan khusus yang dibentuk untuk mengawasi tugas profesi dapat menjatuhkan sanksi administratif kepada anggotanya yang terbukti melanggar kode etik. Selain itu tidak menutup kemungkinan bahwa ia dapat pula dikenakan sanksi pidana apabila terbukti memenuhi unsur-unsur tindak pidana yang diatur dalam undang-undang. Tuntutan terhadap malpraktik kedokteran seringkali kandas di tengah jalan karena sulitnya pembuktian. Dalam hal ini pihak dokter perlu membela diri dan mempertahankan hak-haknya dengan mengemukakan alasan-alasan atas tindakannya (Adi, 2013, h, 267-81).

Berdasarkan latar belakang di atas, tulisan ini akan mengkaji tentang sanksi-sanksi administratif terhadap malpraktik dokter dan rumah sakit ditinjau berdasarkan hukum positif yang berlaku di Indonesia. Permasalahan dalam penelitian ini dirumuskan dalam pertanyaan sebagai berikut: bagaimakah pertanggungjawaban dokter dan rumah sakit terhadap malpraktik dokter ditinjau dari perspektif hukum positif Indonesia?

Menurut Fuady (2005, h. 2), agar suatu tindakan dokter dapat digolongkan sebagai tindakan malpraktek haruslah memenuhi elemen-elemen yuridis sebagai berikut:

a. Adanya tindakan, dalam arti "berbuat" atau "tidak berbuat" (pengabaian);

b. Tindakan tersebut dilakukan oleh dokter atau oleh orang di bawah pengawasannya (seperti oleh perawat), bahkan juga oleh penyelia fasilitas kesehatan, seperti rumah sakit, klinik, apotik, dan lain-lain

c. Tindakan tersebut berupa tindakan medik, baik berupa tindakan diagnostik, terapi, atau managemen kesehatan

d. Tindakan tersebut dilakukan terhadap pasiennya;

e. Tindakan tersebut dilakukan secara:

1) Melanggar hukum, dan atau; 
Jurnal Ilmu Hukum

FAKULTAS HUKUM UMSU
Sanksi Administratif Terhadap...(Marjan Miharja)

Volume 5 Nomor 1, Januari - Juni 2020, 51-56

DOI: https://doi.org/10.30596/dll.v5i1.3445

2) Melanggar kepatutan, dan atau;

3) Melanggar kesusilaan, dan atau;

4) Melanggar prinsip-prinsip profesionalitas.

f. Dilakukan dengan kesengajaan atau ketidak hati-hatian (kelalaian, kecerobohan)

g. Tindakan tersebut mengakibatkan pasiennya mengalami :

1) Salah tindak, dan atau;

2) Rasa sakit, dan atau;

3) Luka, dan atau;

4) Cacat, dan atau;

5) Kematian, dan atau;

6) Kerusakan pada tubuh dan atau jiwa, dan atau;

7) Kerugian lainnya terhadap pasien yang menyebabkan dokter harus bertanggungjawab secara administrasi, perdata, maupun pidana.

Malpraktek medik dapat masuk ke dalam ranah hukum pidana apabila memenuhi syarat-syarat dalam 3 (tiga) aspek, yaitu:

a. Syarat sikap batin dokter

b. Syarat dalam perlakuan medis, dan

c. Syarat mengenal akibat.

Menurut Chazami (2007, h. 81) pada dasarnya syarat dalam sikap batin adalah syarat sengaja atau culpa yaitu wujud perbuatan dalam melakukan tindakan medik, syarat perlakuan medis adalah perlakuan medis yang menyimpang, dan syarat akibat adalah syarat mengenai timbulnya kerugian bagi kesehatan atau nyawa pasien.

\section{METODE PENELITIAN}

Penelitian hukum merupakan suatu bentuk kegiatan ilmiah, yang didasarkan pada metode, sistematika, dan pemikiran tertentu, yang bertujuan untuk mempelajari suatu atau beberapa gejala hukum tertentu, dengan jalan menganalisisnya. Di samping itu juga diadakan pemeriksaan yang mendalam terhadap suatu faktor hukum tersebut, untuk kemudian mengusahakan suatu pemecahan atas permasalahan-permasalahan yang timbul di dalam gejala yang bersangkutan. Adapun metode yang digunakan adalah metode penelitian hukum normatif atau metode penelitian hukum kepustakaan adalah metode atau cara yang dipergunakan di dalam penelitian hukum yang dilakukan dengan cara meneliti bahan pustaka yang ada. Sumber data yang dipergunakan dalam penelitian ini merupakan sumber data sekunder dengan bahan hukum primer sekunder dan tersier untuk kemudian dirangkai sedemikian rupa agar dapat di analisis menggunakan metode analisis data kualitatif agar dapat dengan mudah dipahami oleh pembaca.

\section{PEMBAHASAN DAN ANALISIS}

Sanksi Malpraktik dokter dalam Undang-undang Nomor 29 Tahun 2004 Tentang Praktek Kedokteran 
DE LEGA LATA

Jurnal Ilmu Hukum

FAKULTAS HUKUM UMSU
Sanksi Administratif Terhadap...(Marjan Miharja)

Volume 5 Nomor 1, Januari - Juni 2020, 51-56 DOI: https://doi.org/10.30596/dll.v5i1.3445

Berlakunya Putusan Mahkamah Konstitusi No.4/PPU/-V/2007 terhadap uji materil Undang-undang Nomor 29 tahun 2004 Tentang Praktik Kedokteran, maka perubahan pasalpasal yang terdapat dalam undang-undang tersebut adalah sebagai berikut:

a. Pasal 75

Ayat (1) berbunyi:"Setiap Dokter atau dokter Gigi yang dengan sengaja melakukan praktek kedokteran tanpa memiliki surat registrasi sebagaimana dimaksud dalam pasal 29 (1) dipidana dengan pidana penjara paling lama tiga tahun atau denda paling banyak Rp 100.000.000,00 (seratus juta rupiah)

Ayat (2) berbunyi:"Setiap Dokter atau Dokter Gigi warga negara asing yang dengan sengaja melakukan praktek kedokteran tanpa memiliki surat registrasi sebagaimana dimaksud dalam pasal 31 ayat (1) dipidana dengan pidana penjara paling lama tiga tahun atau denda paling banyak Rp 100.000.000,00 (seratus juta rupiah)."

Ayat (3) berbunyi:" Setiap Dokter atau Dokter Gigi warga negara asing yang dengan sengaja melakukan praktek kedokteran tanpa memiliki surat registrasi bersyarat sebagaimana dimaksud dalam pasal 32 ayat (1) dipidana dengan pidana penjara paling lama tiga tahun atau denda paling banyak Rp 100.000.000,00 (seratus juta rupiah)."

b. Pasal 76 berbunyi: "Setiap Dokter atau Dokter Gigi yang dengan sengaja melakukan praktik kedokteran tanpa memiliki izin praktek kedokteran sebagaimana dimaksud dalam pasal 36 dipidana dengan pidana penjara paling lama tiga tahun atau denda paling banyak Rp 100.000.000,00 (seratus juta rupiah).

c. Pasal 79 berbunyi:'Dipidana dengan pidana kurungan paling lama satu tahun atau denda paling banyak Rp 50.000.000,00 (lima puluh juta rupiah) setiap Dokter atau dokter Gigi yang:

1) Dengan sengaja tidak memasang papan nama sebagaimana dimaksud dalam pasal 41 ayat (1)

2) Dengan sengaja tidak membuat rekam medis sebagaimana dimaksud dalam pasal 46 ayat (1)

3) Dengan sengaja tidak memenuhu kewajiban sebagaimana dimaksud sebagaimana dimaksud dalam pasal 51 huruf a, b, c ,d atau e.

\section{Tanggungjawab Rumah Sakit/Instansi Kesehatan lain Atas Tindakan Malpraktek yang Dilakukan Pelayan Kesehatan}

Berkaitan dengan tanggung jawab hukum pemberi pelayanan kesehatan terutama tanggung jawab hukum Rumah Sakit, dalam hal ini sebagai suatu badan hukum yang memilikinya bisa dituntut atas kerugian yang terjadi, bisa melalui dua cara (Tutik dan Febriana, 2010, h. 72):

a. Langsung sebagai pihak-pihak pada suatu perjanjian bila ada wanprestasi;

b. Tidak langsung sebagai majikan bila karyawannya dalam pengertian peraturan perundangundangan melakukan perbuatan melawan hukum. Hukum Perdata membedakan kategori Rumah Sakit selaku pihak tergugat (korporasi) yaitu Rumah Sakit pemerintah dan Rumah Sakit swasta. Berkaitan dengan Rumah Sakit pemerintah, maka manajemen Rumah Sakit pemerintah c.q Dinas Kesehatan/ Menteri Kesehatan dapat dituntut. Menurut Pasal 1367 Kitab Undang-Undang Hukum Perdata, karena pegawai yang bekerja pada Rumah Sakit 


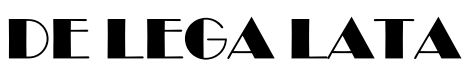

Jurnal Ilmu Hukum

FAKULTAS HUKUM UMSU
Sanksi Administratif Terhadap...(Marjan Miharja)

Volume 5 Nomor 1, Januari - Juni 2020, 51-56 DOI: https://doi.org/10.30596/dll.v5i1.3445

Pemerintah menjadi pegawai negeri dan negara sebagai suatu badan hukum dapat dituntut untuk membayar ganti rugi atas tindakan pegawai negeri yang dalam menjalankan tugasnya merugikan pihak lain. Sedangkan untuk manajemen Rumah Sakit swasta sebagai badan hukum memiliki kekayaan sendiri dan dapat bertindak dalam hukum dan dapat dituntut seperti halnya manusia.

\section{Pertanggungjawaban Administrasi Dokter Dalam Malpraktek Medik}

Menurut Dahlan (1999, h. 54), malpraktek administratif terjadi apabila petugas melanggar hukum administrasi negara. Pemerintah memiliki kewenangan Police Power untuk mengeluarkan berbagai aturan di bidang kesehatan. Apabila aturan tersebut dilanggar, maka tenaga kesehatan tersebut dapat dipersalahkan. Contoh tindakan malpraktek adminstratif yaitu:

a. Menjalankan prakktek tanpa izin;

b. Melakukan tindakan di luar lisensi atau izin yang dimiliki;

c. Melakukan praktik dengan izin yang kadaluarsa.

Kasus malpraktik administratif cukup menarik karena hakikat pelanggarannya masuk ke dalam ranah hukum administrasi negara sehingga sanksinya adalah adminstrasi. Akan tetapi di dalam Pasal 76 Undang-undang Nomor 29 Tahun 2004 tentang Praktek Kedokteran ditegaskan bahwa setiap dokter atau dokter gigi yang dengan sengaja melakukan praktek kedokteran tanpa memiliki surat izin praktik sebagaimana dimaksud dalam pasal 36 dipidana dengan pidana penjara paling lama tiga tahun atau denda paling banyak Rp 100.000.000,00 (seratus juta rupiah). (Catatan: ditambah dengan sanksi administratif langsung dari pemerintah sebagai pengawas kebijakan melalui lembaga terkait dengan pencabutan izin praktek).

\section{KESIMPULAN}

Berdasarkan paparan di atas, dapat disimpulkan bahwasanya malpraktik yang dilakukan oleh dokter dan rumah sakit telah memiliki mekanisme pertanggungjawaban hukum sebagaimana diatur dalam Undang-undang Nomor 29 Tahun 2004 Tentang Praktek Kedokteran. Adapun bagi rumah sakit, dapat dijatuhi sanksi secara langsung dan tidak langsung. Secara administratif, segala bentuk malpraktik yang dilakukan oleh dokter dan rumah sakit dapat diancam dengan sanksi hukuman pidana, sanksi administratif, dan denda. Pasal 76 Undang-undang Nomor 29 Tahun 2004 tentang Praktek Kedokteran ditegaskan bahwa setiap dokter atau dokter gigi yang dengan sengaja melakukan praktek kedokteran tanpa memiliki surat izin praktik sebagaimana dimaksud dalam pasal 36 dipidana dengan pidana penjara paling lama tiga tahun atau denda paling banyak Rp 100.000.000,00 (seratus juta rupiah).

\section{SARAN}

Tindakan malpraktik yang dilakukan oleh dokter dan rumah sakit merupakan tindakan yang dapat membahayakan keselamatan pasien. Meskipun secara regulasi telah terdapat sanksi atas tindakan malpraktik ini, namun diharapkan para dokter dan rumah sakit selaku pemberi layanan kesehatan untuk tidak melakukan tindakan malpraktik. Jika tindakan tersebut masih dilakukan atau muncul, maka diperlukan penindakan hukum yang tegas dari apparat penegak hukum agar kejadian serupa tidak akan terulang lagi di kemudian hari. 


\section{DAFTAR PUSTAKA}

Adi, P. (2013). Formulasi Hukum Penanggulangan Malpraktik Kedokteran. Kanun: Jurnal Ilmu Hukum, 15(2), 267-282.

Kitab Undang-Undang Hukum Perdata

Kitab Undang-Undang Hukum Pidana

Machmud, S. (2012). Penegakan Hukum dan Perlindungan Hukum Bagi Dokter Yang Diduga Melakukan Medikal Malpraktek. Bandung: Karya Putra Darwati.

Munir Fuady, 2005, Sumpah Hippocrates (Aspek Hukum Malpraktek Dokter). Jakarta: Citra Aditya Bakti

Peraturan Konsil Kedokteran Indonesia No. 4 Tahun 2011 tentang Disiplin Profesional Dokter dan Dokter Gigi.

Putusan Mahkamah Konstitusi No.4/PPU/-V/2007 terhadap uji materil Undang-Undang Nomor 29 tahun 2004 Tentang Praktik Kedokteran

Soekanto, S., (1981). Pengantar Penelitian Hukum. Jakarta: UI Press.

\& Mamudji, S., 2009. Penelitian Hukum Normatif Suatu Tinjauan Singkat Cetakan ke-11. Jakarta: PT. Raja Grafindo Persada.

Soetrisno, (2010). Malpraktek Medik Dan Mediasi Sebagai Alternatif Penyelesaian Sengketa. Tangerang: Penerbit PT Telaga Ilmu Indonesia.

Undang-Undang Republik Indonesia Nomor 29 Tahun 2004 Tentang Praktik Kedokteran Lembaran Negara Republik Indonesia Tahun 2004 Nomor 116 dan Tambahan Lembaran Negara Republik Indonesia Nomor 4431

Undang-Undang Republik Indonesia Nomor 8 Tahun 1999 Tentang Perlindungan Konsumen Lembaran Negara Republik Indonesia Tahun 1999 Nomor 42 dan Tambahan Lembaran Negara Republik Indonesia Nomor 3821

Undang-Undang Undang-Undang Republik Indonesia Nomor 23 Tahun 1992 tentang

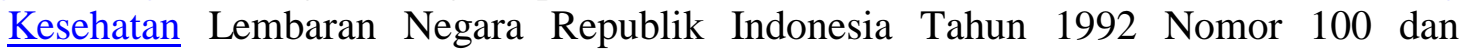
Tambahan Lembaran Negara Republik Indonesia Nomor 3495

Undang-Undang Undang-Undang Republik Indonesia Nomor 6 Tahun 1963 tentang Tenaga Kesehatan Lembaran Negara Republik Indonesia Tahun 1966 Nomor 79 dan Tambahan Lembaran Negara Republik Indonesia Nomor 2576 